\title{
POLIITICAS PARA UNA INSERCIÓN MÁS ESTABLE EN LA ECONOMÍA INTERNACIONAL
}

\section{ESTABLLDAD MACROECONÓMICA}

\section{Antonio Hernández Gamarra*}

Agradezco al señor expresidente doctor Ernesto Samper su amable invitación a compartir — con los participantes en este evento- algunas ideas sobre cómo hacer más estable y menos traumático, el proceso de inserción de Colombia en la economía internacional.

Antes de entrar de lleno en mis comentarios, bueno es hacer una alusión a la manera cómo se hizo la apertura a principios de los años 90 del siglo XX.

En ese entonces se creyó que la liberación comercial tendría un impacto muy favorable en aquellas regiones de nuestro país que tienen una estructura productiva cuya base se sustenta en mayor proporción en bienes de origen primario y cuentan con ventajas competitivas propias de su localización geográfica. Bajo esa esperanza, la Costa Atlántica — se decía— habría de ser una de las regiones más beneficiadas con el proceso de apertura.

Sin embargo, sabemos que ocurrió todo lo contrario porque la liberación comercial y cambiaria golpearon duramente la agricultura moderna y condujeron a un

\section{RESUMEN:}

El Procurador General de la Nación, Antonio Hernández Gamarra critica la falta de una política macroeconómica estable que no se base en el mero recurso de la inversión externa sin control a los capitales que ingresan como elemento fundamental para el desarrollo económico del país. No cree en la cadena inversión, empresa, empleo, sino que en su opinión debe haber unos lineamientos claros con relación a la tributación y a los estímulos a la producción que generen nuevas fuentes de trabajo con miras al acceso de Colombia al mercado mundial en el marco del Tratado de Libre Comercio.

\section{PALABRAS CLAVE:}

Apertura económica, Banco de la República, Capital,
Trabajo, Estabilidadmacroeconómica, Regulación del capital internacional, Crecimiento económico.

\section{ABSTRACT:}

Attorney General, Antonio Hernández Gamarra criticizes the lack of a stable macro-economic policy, not only based on the mere resource of external investment with no control to the capital going into the nation, as fundamental element for the country's economic development. He doesn't believe in the investment/enterprise/employment chain. He highlights the need of establishing clearcut regulations with respect to tax payment and the incentives granted to production units which generate new labor opportunities; with the purpose of expediting the access of Colombia to international markets within the framework of the Free Trade Agreement.

\footnotetext{
* Contralor General de la República. Intervención en el Foro convocado por la Corporación Escenarios y el Politécnico Grancolombiano. Paipa. 2003.
} 
proceso de vuelta a la ganadería extensiva. Como en esa actividad la combinación de factores de producción es adversa al uso del capital y no es trabajo-intensiva se volvió a una generación de empleo precaria en cantidad y calidad.

Aunque fueron varios los factores que condujeron a la crisis del sector agropecuario en los primeros años de los 90, porque simultáneamente se presentó una caída en los precios internacionales, una reducción de los aranceles, una mayor libertad para importar y unas condiciones climáticas adversas, no cabe duda de que la revaluación contribuyó grandemente a ese resultado.

A su vez, la revaluación fue producto de la amnistía a todo tipo de capitales, que se consagró en la norma cambiaria expedida a fines del año de 1990.

Esa liberación del mercado de capitales produjo una avalancha de dólares, de todo género y origen, que condujo, simultáneamente, a la revaluación y a un crecimiento monetario incontrolado. Este último efecto se intentó corregir mediante la elevación de las tasas de interés, lo cual, dada la situación del mercado internacional de capitales, atrajo más inversión externa que generó un círculo vicioso en el manejo de la política cambiaria.

Así, en ese momento, la preocupación de las autoridades se volcó en cómo gastarse los dólares y no en cómo preparar a los sectores productivos para su inserción en la economía internacional.

Esa experiencia sobre la política cambiaria a principios de los años 90 amerita más reflexión de la que ha tenido hasta ahora. Sin duda, la liberación indiscriminada de la cuenta de capitales fue el pecado original de la política económica en ese enton- ces y como resultado de ello se presentó un decaimiento productivo que afectó en especial al sector agropecuario, que hoy difícilmente se repone de esa crisis gracias a la expansión de los cultivos de tardío rendimiento.

La primera lección que debe aprenderse de la experiencia de los años 90 es que no es aconsejable abrirse al exterior en medio de un proceso revaluacionista.

\section{LA ESTABILIDAD MACROECONÓMICA NO BASTA}

Pese a los adversos resultados que produjo la liberación comercial de principios de los años 90 del siglo XX, durante un largo tiempo el país se quedó discutiendo únicamente el tema de la estabilidad macroeconómica.

Ello obedeció a que, por razones ideológicas, algunos de los funcionarios creyeron que la estabilidad macroeconómica era condición necesaria y suficiente para generar el crecimiento económico y por ende, el bienestar. Se consideraba que, si había estabilidad macroeconómica, había inversión, si había inversión, había crecimiento y si había crecimiento se generarían más y mejores empleos.

La verdad es que bajo ese paradigma, durante años se perdió de vista la importancia del crecimiento económico, porque el énfasis de la política se puso solamente en la estabilidad macroeconómica. Se dejó de lado la idea de construir una economía competitiva y, lo que es peor, no se le dio la debida importancia a la calidad del empleo que se estaba generando, ni al bienestar de la población, ni a la reducción de la pobreza.

Además, hoy está claro que a pesar del énfasis que se le ha dado a la estabilidad 
macroeconómica, poco o nada se ha hecho para solucionar el creciente déficit fiscal que afronta el gobierno nacional central.

La realidad al respecto, es que el gobierno nacional central ha mantenido a lo largo de los últimos siete años un déficit cuantioso y en vez de debatir acerca del origen del mismo, el énfasis del discurso oficial se ha encaminado a mostrar la viabilidad de su financiación, sin importar la calidad del gasto público o el tipo de Estado que con él hemos venido construyendo.

Dado el precario empleo que se genera en medio de un pobre crecimiento económico, la segunda lección que tenemos que aprender es que no basta con la estabilidad macroeconómica para reducir la pobreza y mejorar las condiciones de vida de los más necesitados.

\section{REGULACIÓN DEL CAPITAL INTERNACIONAL}

De nuestra propia experiencia y del acontecer internacional ha quedado también clara la necesidad de regular los flujos de capital que llegan desde el exterior a nuestras economías, como condición indispensable para su ordenada inserción a la economía internacional.

Debemos huir del credo que postula que toda inversión extranjera es en sí misma buena para el crecimiento económico y, por lo tanto, debe ser bienvenida.

Bien sabemos que la inversión extranjera que viene con la vocación de jugar en "el casino del mercado de capitales", en busca de ganancias rápidas y salidas precipitadas, debe estar controlada, regulada y por sobre todo, supervisada para evitar la vulnerabilidad y volatilidad que sobre la tasa de cambio y la tasa de interés introducen esos agentes económicos.
Esto es muy importante en el caso colombiano porque desafortunadamente nuestra deuda externa, sobre todo la del gobierno nacional, está en manos de unos tenedores de bonos cuya única motivación para ser acreedores de Colombia, es la rentabilidad de los papeles de deuda que se emiten.

Bajo tal motivación, esos inversionistas son especialmente propensos a traer capital cuando juzgan rentables las operaciones de deuda, pero de igual manera, y con especial celeridad, salen del mercado cuando juzgan que el riesgo de esas operaciones es demasiado alto. Para decirlo de manera breve, ese tipo de capital llega con mucha facilidad y se va con más facilidad aún, si no existen regulaciones que eviten esa volatilidad.

En ese sentido, la deuda pública externa de Colombia tiene signos de vulnerabilidad porque casi 11.500 millones de dólares están en manos de los llamados tenedores de bonos y de agentes privados del mercado internacional de capitales, los cuales, llegado el caso, no constituyen ningún grupo válido para la interlocución. Es decir que no resultaría fácil en un caso dado convocar una reunión de tenedores de bonos para conversar sobre la deuda colombiana. Ello es así porque seguramente quienes originalmente compraron la deuda colombiana ya no la tienen en su poder.

Por eso parece conveniente propiciar un cambio en la estructura de la deuda externa colombiana según acreedores, de tal suerte que relativamente crezca más aquella que se origina en el Banco Mundial, en el Banco Interamericano de Desarrollo y en la Corporación Andina de Fomento.

De una parte estas entidades tienen compromisos frente al país y de otra parte, 
en situaciones de emergencia no tendrían la misma percepción del riesgo de los agentes privados, ni la misma urgencia de minimizar pérdidas en caso de una caída en el precio de los bonos colombianos.

En ese sentido, es saludable que en 2003 se haya propiciado por el gobierno una mayor tenencia de deuda con las entidades multinacionales. Sin embargo, es de observar que los llamados créditos especiales que otorgan esas entidades son de muy corto plazo y de elevada tasa de interés. Por ejemplo, un reciente crédito del BID se contrató a cinco años de plazo, con tres de gracia, lo cual pone enorme presión sobre las necesidades de financiamiento externo en un corto término.

\section{DEBILIDAD DEL CRECIMIENTO ECONÓMICO}

El otro problema de orden macroeconómico para una mejor inserción de Colombia en la economía mundial tiene que ver con las bajas tasas de ahorro e inversión que hoy muestra nuestra economía.

La crisis de fines del siglo pasado dejó a la nación colombiana con unas tasas de ahorro e inversión muy alejadas de las de su referente histórico. Tasas de ahorro cercanas al 15\% del PIB son insuficientes para promover un crecimiento alto y sostenido que contribuya a derrotar en forma permanente el desempleo. Esa es una debilidad muy grande porque deja las posibilidades de inversión en manos del capital extranjero y del crédito externo, con las precariedades y vulnerabilidades que ya hemos anotado.

Así las cosas, es necesario entender y actuar bajo la premisa de que la estabilidad macroeconómica es condición necesaria pero no suficiente para promover el crecimiento económico. Por ello mismo el país tiene que volver a diseñar y poner en práctica políticas sectoriales activas, en especial en materia de crédito. Y sobre este aspecto es fundamental no caer en confusiones. Se puede tener una política selectiva de crédito y ser ortodoxo en materia del manejo monetario. Es decir, se puede contar con un banco central vigilante del poder adquisitivo de la moneda, sin que ello sea óbice para que exista una política de crédito selectivo.

En una sociedad como la nuestra, donde la concentración de la propiedad es tan grande y donde los requerimientos para ser banquero deben ser muy exigentes, no existe libertad para entrar al mercado crediticio. De hecho, ello es así en casi todas las economías.

Por lo mismo, en el sector financiero se generan rentas oligopólicas que deben estar sujetas en algún grado a tasas de tributación especial. La manera como se da esa tributación, en la práctica, es a través de la inversión forzosa de los bancos y demás intermediarios financieros. En efecto, esa inversión forzosa que se remunera a tasas de interés inferiores a las del mercado es el tributo que se paga por tener el privilegio de la emisión secundaria y de ser un agente activo en el mercado crediticio.

Si el crédito dirigido se hace de la manera descrita, con cargo al balance de los intermediarios financieros y no con cargo al balance del Banco Central, se puede ser ortodoxo en materia monetaria y heterodoxo en materia de la dirección del crédito. Por ello desde siempre he sido partidario de la inversión forzosa que con parte de sus recursos deben hacer los intermediarios financieros.

De allí que al inicio del gobierno del presidente Samper se hiciera tanto énfa- 
sis en fortalecer a Finagro y en desarrollar políticas para poner en marcha el incentivo a la capitalización rural (ICR). Porque la promoción y el estímulo a la inversión privada en esos casos se hacía con cargo al presupuesto nacional (por medio del ICR) o por medio de las inversiones forzosas que hacía el sistema financiero para posibilitar el funcionamiento de Finagro.

El otro instrumento valioso para canalizar créditos y por ese medio impulsar el crecimiento económico, tiene que ver con el crédito destinado a la vivienda, en especial a la de interés social.

Desafortunadamente esta última canalización no se prosigue con el interés que amerita ya que no existe una buena base de información estadística para saber si el sistema financiero cumple con las regulaciones, ni para chequear que el cumplimiento de las disposiciones termine efectivamente promoviendo la construcción de la vivienda de interés social.

De todas maneras, la irrigación del crédito a sectores específicos es solo un ejemplo de cómo la política económica debería focalizarse hacia actividades específicas para promover un más alto crecimiento económico.

De igual manera una política activa para promover la competitividad y la modernización del aparato productivo debiera hacer parte insoslayable de ese propósito.

\section{INDEPENDENCIA DEL BANCO DE LA REPÚBLICA}

El debate sobre la independencia del Banco de la República es por supuesto muy relevante para la discusión que nos ocupa. En mi opinión, la reforma de 1991, contra lo que muchos creen, no se produjo como resultado exclusivo del llamado consenso de Washington. Antes de ese consenso en el país existía una profunda insatisfacción con la organización institucional que se había creado para manejar la moneda y el crédito. Desde el inicio de las funciones de la Junta Monetaria, en 1963, el ex ministro Alfonso Palacio Rudas y el profesor Lauchlin Currie fueron muy críticos del manejo de la política monetaria y crediticia. Y sobre todo del hecho de que los "ministros del gasto", como los llamaba Palacio Rudas, tuvieran asiento en la Junta Monetaria.

Por tanto, en buena parte la independencia del Banco de la República consagrada constitucionalmente en 1991 estuvo atravesada por la obsesión de Alfonso Palacio Rudas de que la moneda fuese manejada por unos magistrados que no dependiesen del poder ejecutivo y que no fuesen representantes de sectores económicos específicos.

Veamos esto con algún detalle. A partir de 1973 se produjo un pacto implícito entre las élites colombianas para que casi todos los sectores que se vieran afectados por la inflación tuviesen maneras de compensar esos negativos efectos. $O$ por lo menos que parte de los impactos de la inflación se les neutralizaran a través del sistema de crédito subsidiado que se instituyó en el Banco de la República.

Esa tendencia fue muy clara: primero se creó el Fondo Financiero Agropecuario, después el Fondo Financiero Industrial, luego el Fondo de Inversiones Privadas, el Fondo Financiero Eléctrico, el Fondo de Exportaciones, el Fondo de Obras Públicas y así sucesivamente. Cada gremio o grupo de interés buscó la manera de crear un fondo de financiamiento que les garantizara que a la hora de restringir la cantidad de dinero en circulación no afectara su 
liquidez y a la hora de que subiera la tasa de interés no se vieran obligados a pagar ese mayor costo.

Ese acuerdo implícito había empezado a hacer crisis hacia fines de los años 80 y fue eso lo que en buena parte condujo, junto con el consenso internacional, a crear un banco central independiente.

Pero más allá del tema de la independencia, lo que resulta fundamental en la Constitución de 1991, en relación con la política crediticia, es que se instituyó la prohibición de que el Banco Emisor le otorgase créditos al sector privado. Esta fue la disposición más igualitaria de la norma constitucional. Los pobres por definición no tienen créditos porque no tienen garantías. Entonces al prohibir los préstamos al sector privado se igualó a los pobres con los más pudientes y se les cerró una importante válvula al proceso inflacionario.

El Banco Central genera utilidades que se entregan al gobierno y van al presupuesto nacional para financiar gastos en general. Cuando hay crédito subsidiado, las utilidades del Emisor son menores y entonces parte de los impuestos se asignan de manera arbitraria a determinados sectores y sin ley preexistente. Por lo tanto, la prohibición del crédito al sector privado por parte del Banco Emisor debe preservarse hacia el futuro.

Eso no significa no hacer una política de crédito dirigido como ya fue explicado en la sección anterior.

Además de esa política de crédito dirigido se requiere mucha más coordinación entre el Banco de la República y el Gobierno en términos del diseño de la política económica ya que la otra debilidad enorme es la falta de decisión política para afrontar con seriedad la discusión del problema fiscal del gobierno nacional central. A ese propósito cada cierto tiempo se buscan soluciones parciales, hay una reforma tributaria cada tanto, se buscan recursos para financiar los faltantes del gobierno, pero no se entra a discutir cuál es el fin último de la política fiscal, cuál es el Estado que queremos, cuál necesitamos, qué tipo de inversión en infraestructura se requiere, entre otros interrogantes. Es decir, falta saber qué Estado estamos construyendo para insertarnos en la economía internacional. 